\title{
Shell coal IGCCS with carbon capture: Conventional gas quench vs. innovative configurations
}

\author{
Emanuele Martelli \\ Thomas Kreutz ${ }^{\mathrm{b}}$ \\ Michiel Carbo ${ }^{c}$ \\ Stefano Consonni ${ }^{\mathrm{a}}$ \\ Daniel Jansen ${ }^{c}$
}

\author{
${ }^{\text {aP }}$ olitecnico di Milano, Via Scalabrini 76, Piacenza, Italy \\ ${ }^{b}$ Princeton University, Guyot Hall, Room 129, Princeton, NJ, USA \\ ${ }^{\circ}$ Energy Research Centre of the Netherlands, P.O. Box 1, 1755 ZG, Petten, The Netherlands
}

Published in Applied Energy 88 (2011) 3978-3989 


\title{
Shell coal IGCCS with carbon capture: Conventional gas quench vs. innovative configurations
}

\author{
Emanuele Martelli ${ }^{\mathrm{a}, *}$, Thomas Kreutz ${ }^{\mathrm{b}}$, Michiel Carbo ${ }^{\mathrm{c}}$, Stefano Consonni ${ }^{\mathrm{a}}$, Daniel Jansen ${ }^{\mathrm{c}}$ \\ a Politecnico di Milano, Via Scalabrini 76, Piacenza, Italy \\ ${ }^{\mathrm{b}}$ Princeton University, Guyot Hall, Room 129, Princeton, NJ, USA \\ ${ }^{\mathrm{c}}$ Energy Research Centre of the Netherlands, P.O. Box 1, 1755 ZG, Petten, The Netherlands
}

\section{A R T I C L E I N F O}

\section{Article history:}

Received 10 September 2010

Received in revised form 23 March 2011

Accepted 21 April 2011

Available online 23 May 2011

\section{Keywords:}

IGCC

Shell gasifier

$\mathrm{CO}_{2}$ capture

Process modeling

Plant optimization

WGS

\begin{abstract}
A B S T R A C T
The Shell coal integrated gasification combined cycle (IGCC) based on the gas quench system is one of the most fuel flexible and energy efficient gasification processes because is dry feed and employs high temperature syngas coolers capable of rising high pressure steam. Indeed the efficiency of a Shell IGCC with the best available technologies is calculated to be $47-48 \%$. However the system looses many percentage points of efficiency (up to 10) when introducing carbon capture. To overcome this penalty, two approaches have been proposed. In the first, the expensive syngas coolers are replaced by a "partial water quench" where the raw syngas stream is cooled and humidified via direct injection of hot water. This design is less costly, but also less efficient. The second approach retains syngas coolers but instead employs novel water-gas shift (WGS) configurations that requires substantially less steam to obtain the same degree of $\mathrm{CO}$ conversion to $\mathrm{CO}_{2}$, and thus increases the overall plant efficiency. We simulate and optimize these novel configurations, provide a detailed thermodynamic and economic analysis and investigate how these innovations alter the plant's efficiency, cost and complexity.
\end{abstract}

(c) 2011 Elsevier Ltd. All rights reserved.

\section{Introduction}

In a world with a rapidly expanding appetite for energy and rising concentrations of greenhouse gases, the use of coal as a primary energy source engenders both heightened interest and concern. Coal is the most abundant and least expensive fossil fuel, but also the most carbon intensive. Various gasification technologies enable the conversion of coal into a synthesis gas that can be further processed into common energy carriers such as electricity and synthetic fuels (e.g. hydrogen, natural gas, and liquid transportation fuels). Gasification also provides some of the least costly methods for large scale $\mathrm{CO}_{2}$ capture for sequestration in deep geologic formations away from the atmosphere.

Numerous studies indicate that bituminous coal-based electric power with $\mathrm{CO}_{2}$ capture is less costly using integrated gasification combined cycles (IGCC) instead of standard pulverized coal (PC) steam electric plants [1,2]. For lower rank subbituminous coals and lignites, which comprise fully half of the world's coal reserves [3], the relative economics are less clear. To help clarify this issue, we investigate the thermodynamic and economic performance of

\footnotetext{
* Corresponding author. Tel.: +39 052335 6894; fax: +39 0523623097.

E-mail addresses: emanuele.martelli@polimi.it (E. Martelli), kreutz@princeton. edu (T. Kreutz), carbo@ecn.nl (M. Carbo), stefano.consonni@polimi.it (S. Consonni), jansen@ecn.nl (D. Jansen).
}

three different variants of one particular type of coal-based IGCC plants that is likely to be able to economically convert all coals into electricity and other energy carriers: pressurized, entrained flow, oxygen-blown gasification, with coal drying and dry feeding into the gasifier. All plants in this work use bituminous coal; a forthcoming study addresses the effect of coal rank on plant performance and economics.

Commercial plants of this type (e.g. that use the Shell Coal Gasification or Siemens Fuel Gasification Process) typically employ high temperature heat exchangers to cool down the hot (about $900{ }^{\circ} \mathrm{C}$ ) synthesis gas by generating high pressure steam prior to syngas cleaning and chemical processing. In plants with $\mathrm{CO}_{2}$ venting, the high cost of these "syngas coolers" (SC) is generally offset by significantly increased plant efficiency. However, costly syngas coolers are often not well matched to $\mathrm{CO}_{2}$ capture, which requires a relatively moist syngas; much of the generated steam must be used for syngas humidification required by the downstream water-gas shift (WGS) reaction necessary for high levels of $\mathrm{CO}_{2}$ capture. In this regard, dry feed gasifiers are at a disadvantage relative to coal-water slurry fed gasifiers (e.g. GE Energy and ConocoPhillips E-Gas ${ }^{\mathrm{TM}}$ ) which generate a more humid syngas; often, additional steam is not required prior to WGS. To address this issue, Shell recently filed a patent application for a "partial water quench" whereby the hot raw syngas is cooled by direct water injection [4]. This system both humidifies the syngas and eliminates the costly high temperature syngas coolers. 


\begin{tabular}{|c|c|c|c|}
\hline \multicolumn{2}{|c|}{ Abbreviations and symbols } & O\&M & operation and maintenance \\
\hline AGR & acid gas removal & $p$ & absolute pressure, bar \\
\hline ASU & (stand-alone, cryogenic) air separation unit & $\mathrm{pp}$ & percentage points \\
\hline BOP & balance of plant & $q$ & mass flow rate, $\mathrm{kg} / \mathrm{s}$ \\
\hline COMPR & compressor & $Q C$ & a particular plant configuration, defined below \\
\hline CCR & annual capital charge rate & SC & syngas cooler \\
\hline $\begin{array}{l}\text { CCS } \\
d p\end{array}$ & $\mathrm{CO}_{2}$ capture and storage & $S C$ & a Shell IGCC equipped with a conventional two-stage \\
\hline $\begin{array}{l}d p \\
\mathrm{ECON}\end{array}$ & $\begin{array}{l}\text { infinitesimal pressure drop, bar } \\
\text { economizer }\end{array}$ & $S E$ & $\begin{array}{l}\text { sour WGS unit for CCS, as defined in Section } 2 \\
\text { a Shell IGCC equipped with the novel ECN WGS unit for }\end{array}$ \\
\hline ECN & Energy Research Centre of the Netherlands & & CCS, as defined in Section 2 \\
\hline GE & general electric & $S N$ & a Shell IGCC equipped with an innovative high efficiency \\
\hline HRSC & heat recovery steam cycle & SG & synthesis gas, or syngas \\
\hline HRSG & heat recovery steam generator & $\mathrm{SH}$ & superheater \\
\hline IDC & interest during construction & ST & steam turbine \\
\hline IGCC & integrated gasification combined cycle & TIT & turbine inlet temperature, ${ }^{\circ} \mathrm{C}$ \\
\hline $\mathrm{L} / \mathrm{G}$ & liquid-to-gas mass ratio & TOT & turbine outlet temperature, ${ }^{\circ} \mathrm{C}$ \\
\hline LEAP & Laboratorio Energia Ambiente Piacenza & TPC & total overnight plant cost \\
\hline LCOE & levelized cost of electricity & TPI & total plant investment (TPC + IDC) \\
\hline LHV & lower (or net) heating value & $T_{\text {sat }}$ & saturation temperature, ${ }^{\circ} \mathrm{C}$ \\
\hline LLT & extra low temperature & $v$ & specific volume, $\mathrm{m}^{3} / \mathrm{kg}$ \\
\hline LP & low pressure ( $3-15$ bar) & VGV & variable (air inlet) guide vanes \\
\hline LT & low temperature & WGS & water-gas shift \\
\hline MDEA & $\mathrm{N}$-methyl-diethanolamine & $x_{\mathrm{A}}$ & volume fraction of component $\mathrm{A}$ \\
\hline
\end{tabular}

Researchers at the Energy Research Centre of the Netherlands (ECN) have recently developed an advanced WGS design that significantly reduces the flow of steam required for conversion of $\mathrm{CO}$ and $\mathrm{H}_{2} \mathrm{O}$ to $\mathrm{CO}_{2}$ and $\mathrm{H}_{2}$ [5]. This system, which is modeled and optimized in this study, has recently been implemented at pilot scale at NUON's Buggenum IGCC plant in the Netherlands. In addition, we investigate an alternative advanced WGS layout specifically designed and optimized to further minimize the steam consumption and thus the carbon capture penalty.

This study compares the thermodynamic and economic performance of a bituminous coal-based IGCC plant using Shell gasification technology - with and without $\mathrm{CO}_{2}$ capture - using either the standard gas quench or the partial water quench as syngas cooling method and either the conventional two-stage sour WGS or one of the two advanced WGS designs. The plants are designed, modeled in detail and optimized to maximize the net electric efficiency, using both exergy analysis and numerical optimization algorithms. Our goal is to understand what the preferred IGCC design is for dry feed, entrained flow gasifiers with relatively high levels of carbon capture ( $>90 \%)$.

\section{Methodology}

We model four cases, three with $\mathrm{CO}_{2}$ capture:

SV - a Standard (i.e. with syngas coolers) Shell coal gasifierbased IGCC plant with syngas coolers and $\mathrm{CO}_{2}$ Venting,

SC - a Standard Shell IGCC plant with $\mathrm{CO}_{2}$ capture that uses a Conventional two-stage WGS unit,
$\boldsymbol{S E}$ - a Standard Shell IGCC plant with $\mathrm{CO}_{2}$ capture that uses the advanced $\boldsymbol{E C N}$ WGS design,

SN - a Standard Shell IGCC plant with $\mathrm{CO}_{2}$ capture that uses an optimized New WGS configuration derived from the ECN design,

QC - a partial water Quench Shell IGCC plant with $\mathrm{CO}_{2}$ capture, using a Conventional two-stage WGS unit.

This research entailed seven primary tasks: (1) building a detailed model of the Shell coal gasification process using Aspen Plus chemical process modeling software [6], (2) calibrating the model by matching key component data and process flows to the detailed information provided in Refs. [7-9] which describe standard Shelland Prenflo-based IGCC plants using bituminous coal, (3) investigating the optimal design of a partial water quench + wet scrubber + WGS system for Shell IGCC with $\mathrm{CO}_{2}$ capture, (4) building the ECN WGS and coupling it to a standard Shell IGCC plant, (5) simulating the General Electric (GE) 9FB gas turbine (burning $\mathrm{H}_{2}-$ rich syngas) using the "Gas/Steam" (GS) simulation code developed at Politecnico di Milano and presented in [10,11,15,18], (6) configuring and optimizing the layout of the heat recovery steam cycle (HRSC) for each plant using a new method developed by Martelli $[12,13]$ that maximizes the power output of the steam cycle, and (7) adding the cost framework required for a full techno-economic comparison between cases. Given that the first generation of IGCC power plants with $\mathrm{CO}_{2}$ capture are likely to be operated as base-load plants, analyses of load-following performance and off-design calculations were not performed in this study. Indeed, commercially available gasification processes and 
air separation units (ASU) have only a limited ability to operate at part-loads.

\section{System design overview}

In order to make "fair" comparisons between the four cases studied here and thus highlight their intrinsic differences, the basic plant configuration, key design parameters and modeling assumptions are held fixed for all cases. All plants share a common design: a Shell coal gasifier with a stand-alone cryogenic ASU, two GE 9FB gas turbines, and a three pressure level HRSG with reheat. Plants with $\mathrm{CO}_{2}$ capture have the same extent (98\%) of $\mathrm{CO}$ conversion in the water-gas shift (WGS) unit, and employ a two-stage Selexol ${ }^{\mathrm{TM}}$-based acid gas removal unit (AGR), $\mathrm{CO}_{2}$ compressor and syngas saturator upstream of the gas turbines. As a result, thermodynamic (and economic) differences observed between cases $\boldsymbol{S C}, \boldsymbol{S E}$ and $\boldsymbol{S N}$ should reflect only the design of the WGS unit, i.e., the number of reactors, their layout and downstream heat recovery. Cases $\boldsymbol{Q C}$ and $\boldsymbol{S C}$ differ only in the method of syngas cooling and humidification upstream of identical WGS units.

\subsection{Gasifier Island and ASU (common units)}

The basic design of the gasification island is illustrated in Fig. 1 (which represents the overall plant $\boldsymbol{S C}$ ); calculation details and assumptions are given in Table A1. East Australian bituminous coal (Table 1 ) is milled, dried to a moisture level of $2 \%$ (weight basis), and fed into the gasifier via lock-hopper pressurization using $\mathrm{N}_{2}$ as a transport gas.
Table 1

Composition (in\%, weight basis) and heating value of as received East Australian bituminous coal used here [9].

\begin{tabular}{llll}
\hline $\mathrm{C}$ & 64.60 & Moisture & 9.5 \\
\hline $\mathrm{H}$ & 4.38 & Ash & 12.2 \\
\cline { 3 - 4 } $\mathrm{O}$ & 7.05 & & \\
$\mathrm{~N}$ & 1.39 & & $\mathrm{MJ} / \mathrm{kg}$ \\
$\mathrm{S}$ & 0.86 & $\mathrm{HHV}$ & 27.063 \\
$\mathrm{Cl}$ & 0.02 & LHV & 25.874 \\
\hline
\end{tabular}

The coal is gasified in the presence of medium pressure (MP) steam and 95\% oxygen from a stand-alone cryogenic air separation unit (ASU). Gasification is modeled using full chemical equilibrium at 38.5 bar and $1390{ }^{\circ} \mathrm{C}$. Steam to oxidant flows are set by maximizing the LHV of the raw synthesis gas (SG) exiting the gasifier while fixing the heat loss to the membrane wall at $1.4 \%$ of the input coal HHV. The single-pass carbon conversion is $97.3 \%$; with recycled fly ash (minus 5\% bleed), the overall carbon conversion is $99.8 \%$. Much of the input mineral matter (34.5\%) exits the bottom of the gasifier as a vitreous slag; the remainder is captured as fly ash (after syngas cooling) by a ceramic filter and recycled back to the coal milling/drying unit. Heat for drying is provided by burning $1 \%$ of the scrubbed syngas. All gasifier island parameters (reported in Table A1) were "tuned" in order to closely match the detailed data on syngas flow and composition from the gasification island provided by Shell [9].

\subsection{Case $\mathbf{S V}$}

In the standard Shell IGCC plant, the raw syngas exiting the gasifier is first quenched to $900{ }^{\circ} \mathrm{C}$ (to solidify molten ash) by a stream

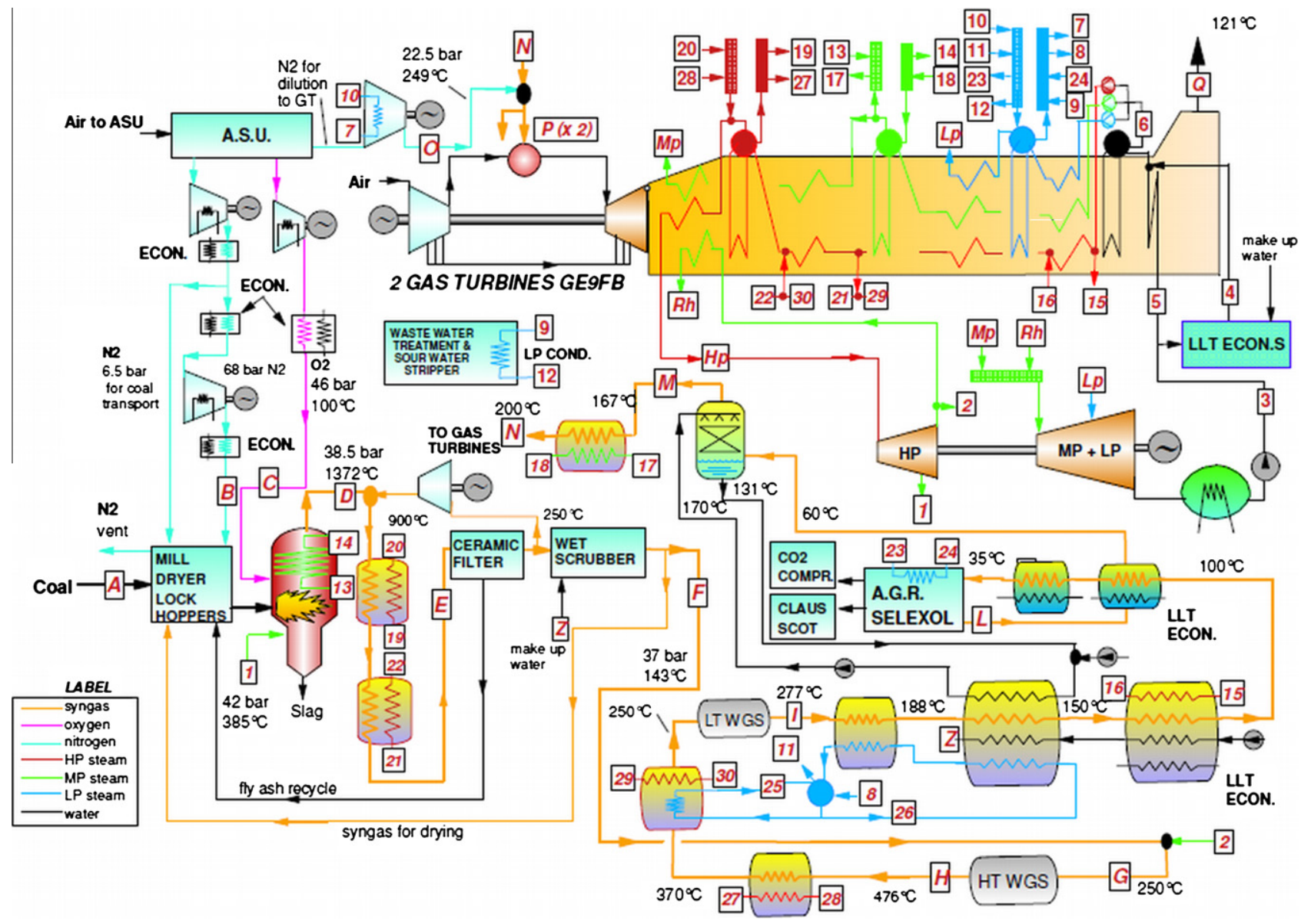

Fig. 1. Plant schematic for case $\boldsymbol{S C}$, the standard Shell IGCC $+\mathrm{CO}_{2}$ capture with a conventional WGS. 
of recycled, cooled, ash-free syngas and is then cooled to $250{ }^{\circ} \mathrm{C}$ in syngas coolers that economize and evaporate high pressure (HP) feedwater to generate HP steam for the bottoming cycle. Dry particulate filters remove fly ash from the syngas, which is then divided ( $\sim 45 \%$ is sent to the recycle compressor for the gas quench) and sent to a countercurrent flow wet scrubber that removes trace particulate matter and water soluble contaminants. Scrubbed syngas is then warmed to $200^{\circ} \mathrm{C}$ and passed through a COS hydrolysis unit that converts $\mathrm{COS}$ to $\mathrm{H}_{2} \mathrm{~S}$, and $\mathrm{HCN}$ to $\mathrm{NH}_{3}$. The syngas is cooled to $40{ }^{\circ} \mathrm{C}$ and sent to a Sulfinol $\mathrm{M}^{\mathrm{TM}}$ acid gas removal (AGR) system that strips out virtually all of the $\mathrm{H}_{2} \mathrm{~S}$ (and $16 \%$ of the $\mathrm{CO}_{2}$ ) which is sent to an $\mathrm{O}_{2}$-blown Claus unit for conversion to elemental sulfur. The Claus tailgas is hydrogenated and recycled to the AGR. The sweet syngas exiting the AGR is heated to $350{ }^{\circ} \mathrm{C}$ and burned in two GE 9FB gas turbines (GT). $\mathrm{NO}_{x}$ emissions from the GT are limited to $\sim 25$ ppmv $\left(15 \% \mathrm{O}_{2}\right)$ by diluting the syngas with all the available $\mathrm{N}_{2}$ and some steam in order to lower the stoichiometric flame temperature to $2027{ }^{\circ} \mathrm{C}$ [15]. ${ }^{1}$ Heat is efficiently recovered from the turbine exhaust in a triple pressure level (plus reheat) heat recovery steam generator (HRSG) coupled to a single steam turbine. A high degree of heat integration is employed between the syngas train and the steam cycle, and design is optimized to achieve maximum efficiency $[12,13]$.

\subsection{Case $\mathbf{S C}$}

Our design for the standard Shell IGCC with $\mathrm{CO}_{2}$ capture (represented in Fig. 1) mirrors that of Ref. [1] to facilitate model calibration and verification; however, we adopt a somewhat higher minimum input steam-to-CO $(\mathrm{S} / \mathrm{CO})$ ratio of 2.5 in order to avoid carbon formation on the WGS catalysis [14] and also to achieve an "overall carbon capture fraction"2 of 93.1\%. The scrubbed syngas is pre-heated, combined with a large flow of superheated MP steam bled from the steam turbine, and sent to a conventional two-stage sour WGS unit (with sulfur-tolerant Co-Mo catalysts) that converts $98 \%$ of $\mathrm{CO}$ to $\mathrm{CO}_{2}$ and $\mathrm{H}_{2}$. The syngas enters/exits the high temperature (HT) WGS reactor at $250 / 466{ }^{\circ} \mathrm{C}$; it is then cooled and enters/exits the low temperature (LT) WGS reactor at $250 / 276{ }^{\circ} \mathrm{C}$. The assumptions adopted to model the WGS reactors are given in Table A1. The shifted syngas is cooled to $38^{\circ} \mathrm{C}$, sent to the Selexol ${ }^{\mathrm{TM}}$ process for $\mathrm{H}_{2} \mathrm{~S}$ and $\mathrm{CO}_{2}$ selective removal, saturated with water, diluted with some $\mathrm{N}_{2}$ supplied by a dedicated compressor, heated to $200^{\circ} \mathrm{C}$, and burned in the gas turbines. According to [1], the two-stage selective Selexol process is capable of capturing $96.54 \%$ of the inlet $\mathrm{CO}_{2}$, and co-capturing $0.53 \%$ of $\mathrm{H}_{2}$ and $0.44 \%$ of $\mathrm{CO}$. Thus, the overall carbon capture level (defined as mole flow rate of captured carbon divided by mole flow rate of carbon in fuel at inlet) is $93.0 \%$. The captured $\mathrm{CO}_{2}$ stream is dehydrated and compressed from 1.8 to 150 bar for pipeline transport and storage in geologic formations; the $\mathrm{H}_{2} \mathrm{~S}$ rich stream is treated in a conventional Claus unit followed by a Shell Claus Offgas Treating (SCOT) process.

\subsection{Case $\boldsymbol{S E}$}

In contrast to the two-stage conventional WGS unit, ${ }^{3}$ the advanced ECN system [5], as implemented here (reported in Fig. 2), consists of four sequential, adiabatic sour shift reactors, each of which is fed a fraction of the original syngas stream plus the

\footnotetext{
${ }^{1}$ In case $\boldsymbol{S V}$, the most efficient method of syngas dilution involves using all of the available $\mathrm{N}_{2}$ and a small amount of steam. In all $\mathrm{CO}_{2}$ capture cases we first saturate the syngas using low temperature heat that is not otherwise well utilized in the bottoming cycle, and then add $\mathrm{N}_{2}$ as needed to control $\mathrm{NO}_{x}$.

2 Defined here as the fraction of the carbon in the input coal that is retained either as carbon in the gasifier slag/flyslag or as $\mathrm{CO}_{2}$ stored underground.

3 Novel WGS designs that include upstream saturators and downstream desaturators are not considered in this work.
}

requisite amount of either MP steam (reactor 1, as represented in Fig. 2) or $160{ }^{\circ} \mathrm{C}$ water (reactors $2-4$ ) needed to satisfy the requirement adopted here that $\mathrm{S} / \mathrm{CO}=2.5$ at the input of each reactor (in order to avoid carbon formation on the catalyst). Designed specifically to minimize the amount of steam required for the WGS reaction, the ECN system utilizes the concept that, since the WGS reaction consumes only one mole of $\mathrm{H}_{2} \mathrm{O}$ per $\mathrm{CO}$, the $\mathrm{H}_{2} \mathrm{O} / \mathrm{CO}$ ratio within the bed (along the reactant flow path) rapidly exceeds 2.5 as "excess" water accumulates. By splitting the original syngas into multiple fractions and combining the water-laden streams exiting upstream WGS reactors with the feed streams of downstream WGS reactors, the total water consumption is significantly reduced. As discussed below, this has important consequences on both the efficiency and economics of the system.

Configuring the advanced WGS system shown in Fig. 2 is relatively straightforward, with an equal number of free variables and constraints. Making the simplifying assumption that all water input streams have the same temperature, there are ten free variables to be set: four syngas split fractions, four steam/water flows, and the water and steam temperatures. The condition of S/ $\mathrm{CO}=2.5$, and $T=250^{\circ} \mathrm{C}$ at the input of each reactors yields eight constraints; the remaining two are the temperature of MP steam from the steam turbine and the overall CO conversion efficiency. Therefore, a single solution of the above (nonlinear) design problem exists. To have a fair comparison, the same key assumptions adopted to model the WGS reactors of case $\boldsymbol{S C}$ are adopted for cases $\boldsymbol{S E}$ and $\boldsymbol{S N}$ (i.e., those assumptions reported in Table A1). The plant layout for case $\boldsymbol{S E}$ is essentially identical to that shown in Fig. 1, with conventional WGS unit replaced by the ECN system shown in Fig. 2.

\subsection{Case $\mathbf{S N}$}

The water quench employed by the ECN WGS is much more irreversible than the steam injection employed by the conventional WGS layout, as confirmed by the exergy analysis presented in Section 5. It is instructive to quantify in the ECN design the potential gain in efficiency that can be achieved by replacing the water quench with steam injection, followed by syngas cooling. Due to the high temperature of medium pressure steam (via a turbine bleed at $330^{\circ} \mathrm{C}$ ), gas coolers are necessary to bring the syngas temperature to the desired inlet temperature of the downstream reactors (i.e. $250^{\circ} \mathrm{C}$ ). This "alternative" WGS design is shown in Fig. 3. The outlet temperatures of coolers 1,3 and 5 are adjusted to maximize the production of higher pressure steam with a pinch point temperature difference of $15^{\circ} \mathrm{C}$, while the outlet temperatures of coolers 2,4 and 6 are fixed at $250^{\circ} \mathrm{C}$. The addition of syngas coolers increases the degrees of freedom of the design in comparison with the original ECN WGS: steam mass flow rates can be varied without violating the constraints imposed by the inlet temperature of the reactors (these temperatures are set by the syngas coolers). Hence this WGS unit has nine variables (four syngas split fractions, four steam/water flows, and the steam temperature) and only seven constraints (S/ $\mathrm{CO} \geqslant 2.5$ in each reactor, the steam temperature, $T=250^{\circ} \mathrm{C}$ at inlet of the first reactor, the temperature of MP steam and the overall CO conversion efficiency). This provides two degrees of freedom (i.e. number of variables minus number of constraints) for optimizing the design. Further details about the optimization of this WGS layout are in Section 5.

\subsection{Case $\mathbf{Q C}$}

In the partial water quench system with $\mathrm{CO}_{2}$ capture (represented in Fig. 4), the standard syngas cooling system (gas quench via syngas recycle, followed by syngas coolers) of case $\boldsymbol{S C}$ is 


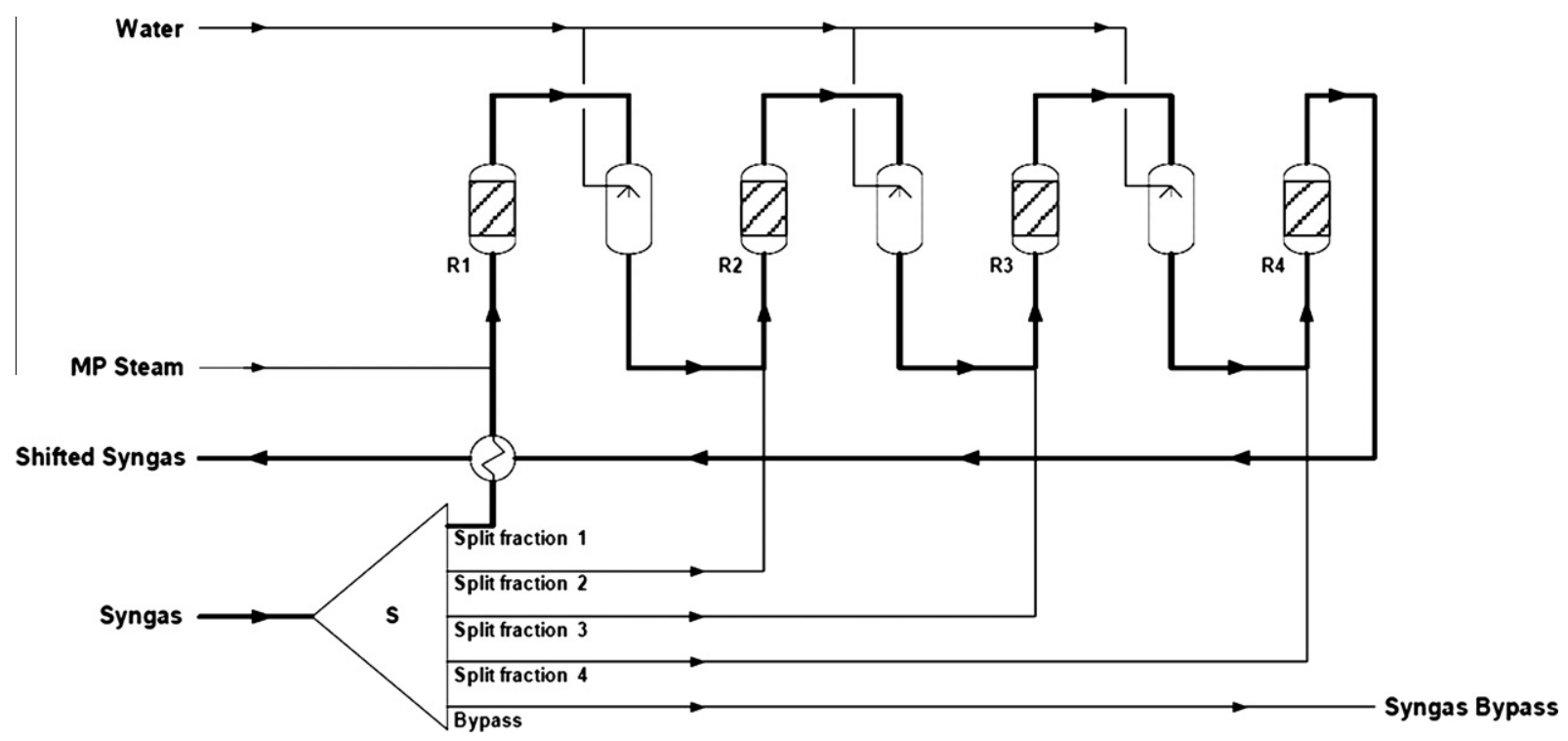

Fig. 2. Layout of the ECN advanced WGS.

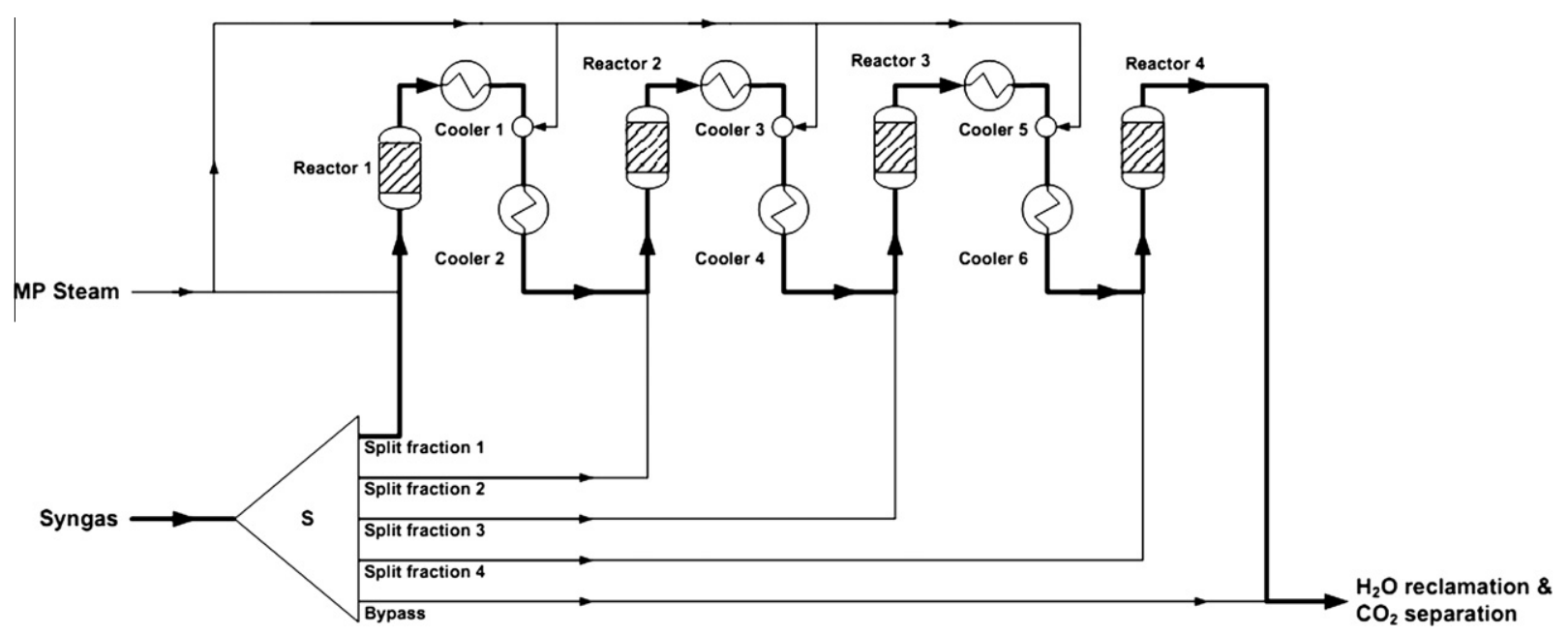

Fig. 3. Layout of the advanced WGS unit to be optimized (employed in plant $\mathbf{S N}$ ).

replaced by a water quench cooling design [4] in which the raw syngas is quenched by a spray of hot $\left(243^{\circ} \mathrm{C}\right)$ water, cooling it to a temperature suitable for the downstream particulate filter. The quenched syngas traverses the filter and is sent to the wet scrubber operating with $170{ }^{\circ} \mathrm{C}$ wash water. The syngas enters/exits the scrubber with a S/CO ratio of $1.96 / 2.2$, and as a result, the flow of MP steam required to achieve the target S/CO ratio of 2.5 is less than $15 \%$ of that required by the standard Shell configuration.

Significant effort was spent optimizing the performance of the partial water quench and wet scrubbing system. Our design goal was to minimize the flow of MP steam to the WGS unit needed to achieve a S/CO ratio of 2.5 in the humidified syngas stream entering the HT-WGS reactor while limiting water vaporization in the wet scrubber (to minimize costs). Five free parameters must be specified: the temperature and flow rate of the quench water, the temperature of an optional scrubber pre-cooler, and the temperature and flow rate of the wash water in the wet scrubber. To speed the evaporation of the quench water droplets into the syngas, and also minimize exergy loss in the quench process, the quench water temperature was set to $243^{\circ} \mathrm{C}$, only a few degrees below the 38.5 bar saturation temperature, $T_{\text {sat }}=248.1^{\circ} \mathrm{C}$. ${ }^{4}$

The wet scrubber was modeled as an adiabatic, countercurrent absorption column with 5 equilibrium stages and a fixed liquid-togas mass ratio ${ }^{5}(L / G)$ of $0.25[16,17]$. Thus constrained, the scrubber has only a limited capability to increase the S/CO ratio of the syngas (Fig. 5). For example, even at the highest wash water temperature of $243{ }^{\circ} \mathrm{C}$ (just below $T_{\text {sat }}$ ), the $\mathrm{S} / \mathrm{CO}$ ratio of dry syngas from a standard Shell gasifier rises from about 0.08 to only 0.3 , requiring the addition of $382 \mathrm{MW}$ of MP steam (this thermal power is obtainable by cooling the given steam mass flow rate to the environment temperature) to achieve the target $\mathrm{S} / \mathrm{CO}$ ratio of 2.5 . In contrast, raw syngas that is

\footnotetext{
${ }^{4}$ The raw syngas could also be quenched in part or totally with steam, but our investigation shows that adding steam to the raw syngas is essentially equivalent to adding it just prior to the WGS unit. In short, adding steam to the quench does not reduce overall steam consumption.

${ }^{5}$ Because a significant fraction of the input water can evaporate into the syngas within the scrubber, we define this fraction as the mass of water exiting the scrubber divided by the mass of syngas entering it.
} 


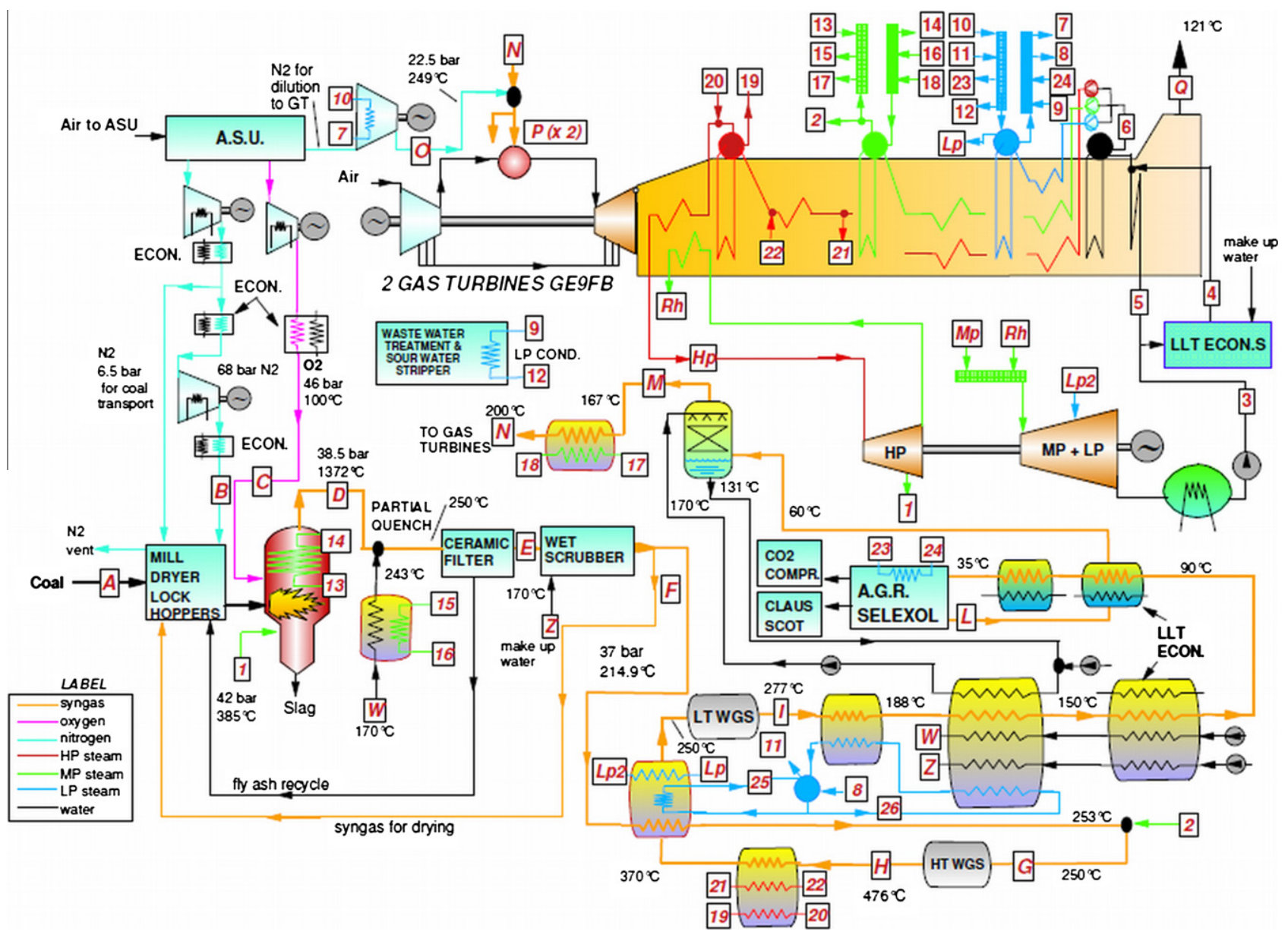

Fig. 4. Plant schematic for case $\boldsymbol{Q C}$, the partial water quench IGCC with the conventional WGS.

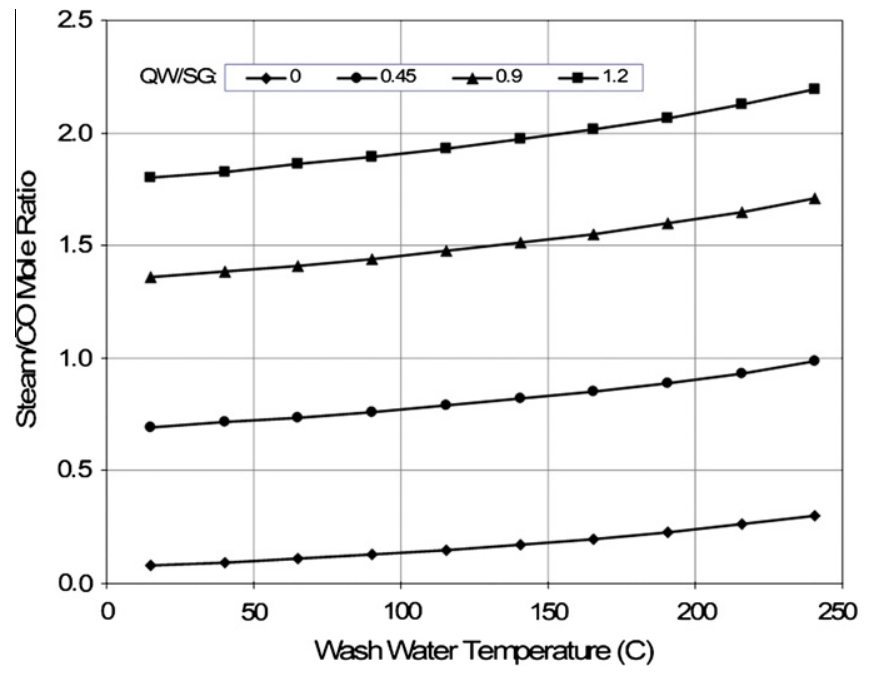

Fig. 5. Steam-to-CO ratio of scrubbed syngas as a function of wash water temperature and quench water-to-syngas mole ratio, $Q W / S G$. The $L / G$ ratio of the scrubber is fixed at 0.25 .

partially quenched with water at quench water-to-syngas mass ratio $(\mathrm{QW} / \mathrm{SG})$ of 1.2 can exit the scrubber with $\mathrm{S} / \mathrm{CO}=2.2$, requiring only 53 MW of MP steam.

In summary, the partial water quench, scrubber, and WGS steam addition are all methods of humidifying the syngas; minimizing the latter two requires maximizing the partial water quench. This is achieved by using quench water that is as hot as possible (i.e. close to $T_{\text {sat }}$ ), and quenching down close to $T_{\text {sat. }}$. Syngas coolers (such as an optional syngas pre-cooler), which reduce the temperature of the syngas without humidifying it, work against these goals. However, the gas quench process with syngas coolers and steam injection for humidification is much less irreversible than the direct water quench: the high temperature heat of the raw syngas can produce high pressure steam that expands in the first section of the steam turbine up to the bleed for the WGS; in the water quench process the high temperature raw syngas is immediately degraded into low temperature heat which may produce only low pressure steam. Comparing the standard Shell (SC) vs. partial water quench configuration $(\mathbf{Q C})$, the former entails more than three times the amount of heat transfer $(440+220 \mathrm{MW}$ vs. $205 \mathrm{MW})$.

With a fixed $L / G$ ratio, the wet scrubber has only a limited ability to alter the humidity of the syngas. Thus, to limit the water vaporization and to optimize the recovery of low temperature heat in the cooling section, the temperature of the wash water is fixed slightly below the syngas dew point $\left(170^{\circ} \mathrm{C}\right.$ for cases $\boldsymbol{S C}$ and $\boldsymbol{Q C}$, and $160{ }^{\circ} \mathrm{C}$ for case $\boldsymbol{S E}$ ).

\section{Power island design and modeling}

The power unit consists of two GE 9FB gas turbines, each with a triple pressure level HRSG integrated with the process (syngas coolers, Selexol reboiler, and sour water stripper.), and a single steam turbine. While the GE 7FB is commercialized for operation on syngas, the 9FB has not yet been so proven. Nevertheless, since 
Table 2

Details of the GE 9FB gas turbine model used here.

\begin{tabular}{|c|c|c|c|c|c|}
\hline \multirow[b]{2}{*}{ GT parameter } & \multirow{2}{*}{$\begin{array}{l}\text { GE 9FB reference data } \\
\text { Natural gas }\end{array}$} & \multicolumn{4}{|c|}{ Calibrated GT model (using “GS” software) } \\
\hline & & Natural gas & SV & $S E$ & $S C, Q C$ \\
\hline TIT (estimated), ${ }^{\circ} \mathrm{C}$ & Unknown & $1,360^{\mathrm{a}}$ & $1,327^{\mathrm{b}}$ & $1,260^{\mathrm{b}}$ & $1,260^{\mathrm{b}}$ \\
\hline Turbine outlet (TOT), ${ }^{\circ} \mathrm{C}$ & 622.8 & 622.7 & 613.3 & 565.1 & 566.4 \\
\hline Air mass flow rate, $\mathrm{kg} / \mathrm{s}$ & 637.13 & 637.13 & 530.45 & 573.5 & 575.43 \\
\hline Fuel mass flow rate, $\mathrm{kg} / \mathrm{s}$ & 16.187 & 16.198 & 132.73 & 69.212 & 65.432 \\
\hline 1st row cooling, $\mathrm{kg} / \mathrm{s}$ & Unknown & 61.022 & 55.507 & 46.262 & 46.516 \\
\hline Flue gas mass flow rate, $\mathrm{kg} / \mathrm{s}$ & 653.317 & 653.33 & 663.26 & 642.72 & 640.86 \\
\hline Net electric power, MW & 272.6 & 272.44 & 313.8 & 296.96 & 296.46 \\
\hline
\end{tabular}

a Estimate of the real TIT, calibrated to reproduce the GT output and TOT.

b TIT de-rated using Eq. (1).

the 9FB is a scaled-up version of the 7FB, it is expected to run on syngas without significant issues. The GT has been modeled using the "Gas/Steam" simulation code $[10,11]$ and the performance estimation method of Chiesa [18].

The GT model was calibrated to reproduce the same output of a GE 9FB burning natural gas, and then adjusted for operating on syngas (see Table 2). We adopt the control strategy discussed in Ref. [15] for operating a syngas-fired GT without major modifications: the turbine inlet temperature (TIT) is fixed at a value consistent with blade lifetime equal to that for NG operation (TIT derating discussed below), and the variable inlet guide vanes (VGV) are partially closed to reduce the compressor air flow. We assume here a constant pressure ratio - that employed for NG; the actual pressure ratio will depend on the actual compressor map (pressure ratio vs. non-dimensional mass flow rate), details of which are confidential and not readily predicted. In general, variations in pressure ratio can be neglected if the compressor air mass flow rate exceeds $\sim 85 \%$ of its design point (NG) value.

We de-rated the TIT to offset the relatively high heat transfer between the $\mathrm{H}_{2} \mathrm{O}$-rich gases and the turbine blades, and thus insure standard blade lifetimes. Rather than using the method of Ref. [15] which adjusts the TIT until critical blade temperatures obtained during syngas operation match those during NG firing (using the same cooling flows), we employed instead the more conservative correlation of Oluyede [19]:

$\Delta T_{\mathrm{TIT}}=13.312 *\left(x_{\mathrm{H}_{2}}\right)^{0.69}$

which, for our shifted syngas, de-rates the TIT by $100{ }^{\circ} \mathrm{C}$ (compared to $35{ }^{\circ} \mathrm{C}$ using the method of Ref. [15]). Note that Eq. (1) expresses $\Delta T_{\mathrm{TIT}}$ in ${ }^{\circ} \mathrm{F} . x_{\mathrm{H}_{2}}$ denotes the volume fraction of $\mathrm{H}_{2}$ in the diluted syngas fed into the combustor.

The GT fuel inlet temperature is another key parameter. High fuel inlet temperatures improve overall cycle efficiency because the thermal energy of pre-heating replaces the chemical energy of syngas. Standard CO-rich syngas can be heated up to $350^{\circ} \mathrm{C}$ without major issues [20], but $\mathrm{H}_{2}$-rich syngas can be safely preheated to only $200-210^{\circ} \mathrm{C}$, just enough to avoid water condensation during gas expansion through the combustor control valve. For these reasons, we adopt an inlet fuel temperature of $350{ }^{\circ} \mathrm{C}$ in case $\mathbf{S V}$, and $200{ }^{\circ} \mathrm{C}$ in the $\mathrm{CO}_{2}$ capture cases.

Downstream of each gas turbine is a triple pressure level HRSG with reheat. The heat integration of each plant was individually optimized using a the methodology recently developed by Martelli $[12,13]$ in which the arrangement of the heat recovery steam network and the design of the heat recovery steam generator (HRSG) are simultaneously optimized. By means of this optimization algorithm (called the "HRSC Optimizer"), steam mass flow rates raised in each tube bank of syngas coolers and HRSG, steam mass flow rates of extractions used by condensers, reboilers and steam users, pressure levels, pressure of turbine extractions, and pinch point temperature differences were numerically optimized to maximize the net electric efficiency of the overall IGCC plants. Within this design methodology, capital costs are not explicitly considered in the objective function, but economic feasibility is obtained by adopting realistic design constraints and criteria derived from the industrial practice. For instance, all syngas coolers were constrained to be either evaporators or economizers with a minimum pinch point temperature difference of $15 \mathrm{~K}$, and $50 \mathrm{~K}$ for the HT syngas cooler. Within the HRSG, pinch point temperature differences were set $\geqslant 8 \mathrm{~K}$, sub-cooling temperature differences (i.e., temperature difference between saturation temperature and economizer exit temperature, adopted to avoid steaming in the economizers) $=3 \mathrm{~K}$, and the superheat/reheat approach temperature difference (i.e., temperature difference between the flue gas and superheated steam at $\mathrm{SH} / \mathrm{RH}$ exit) $\geqslant 25 \mathrm{~K}$. The condenser pressure was assumed equal to 0.05 bar (i.e., we assumed the availability of either a cold river or sea water). These constraints were derived from the industrial design practice for large scale combined cycles. Regarding the intensive decision variables of the steam cycle (i.e., steam pressures and temperatures), we employed a "conservative" set of HRSC parameters in which $p_{\mathrm{HP}} \leqslant 140 \mathrm{bar}, p_{\mathrm{MP}} \geqslant 39 \mathrm{bar}, p_{\mathrm{LP}} \geqslant 5 \mathrm{bar}$, and $T_{\mathrm{SH}}$ (superheat/reheat temperature) $=540^{\circ} \mathrm{C}$. The limit on $p_{\mathrm{HP}}$ was fixed in order to adopt a standard drum type evaporator, the lower bound on $p_{\mathrm{MP}}$ was determined by the direct integration with the Shell gasifier membrane wall (which evaporates MP steam and whose steam pressure must be sufficiently higher than the syngas pressure), the lower bound on $p_{\mathrm{LP}}$ is commonly introduced to avoid expensive oversized pipes, tubes and headers, while $T_{\mathrm{SH}}$ was selected equal to $540{ }^{\circ} \mathrm{C}$ in order to use conventional steam turbines for combined cycles. Detail results of each optimized HRSC are given in Table 3. We also briefly discuss the results of an "aggressive" HRSC parameter set in which $p_{\mathrm{HP}}$ was limited to 170 bar (i.e., assuming to use Benson once-through evaporators, [21]), $p_{\mathrm{MP}}$ is free (i.e., neglecting the issues related to the gasifier membrane wall), $p_{\mathrm{LP}} \geqslant 3$ bar, and $T_{\mathrm{SH}}=545^{\circ} \mathrm{C}$ (i.e., the gas turbine outlet temperature, about $565{ }^{\circ} \mathrm{C}$ for cases with CCS, minus $20 \mathrm{~K}$ of approach point temperature difference)

\section{Plant performance}

Plant performance is given in Tables 3 and 4 .

\subsection{SV: $\mathrm{CO}_{2}$ venting reference case}

The efficiency of the plant without capture, about $48 \%$ LHV, is higher than a similar case presented previously in [22] for three reasons: the GE 9FB is more efficient than the Siemens V94.3A, ${ }^{6}$ the clean syngas is highly pre-heated before entering the combustor, and the heat recovery steam cycle is fully optimized (pressure levels,

\footnotetext{
${ }^{6}$ The pressure ratio is higher: 18.3 vs. 17.0 , the TIT is estimated to be $10{ }^{\circ} \mathrm{C}$ higher and the clean syngas is highly pre-heated before entering the combustor.
} 
Table 3

Details of the optimized HRSC for each case.

\begin{tabular}{|c|c|c|c|c|c|}
\hline HRSC variable & SV & $S C$ & $S E$ & SN & $Q C$ \\
\hline HP-MP-LP pressures, bar & $140-39-5$ & $140-39-5$ & $140-39-5$ & $140-39-5$ & $140-42-5$ \\
\hline HP steam produced, $\mathrm{kg} / \mathrm{s}$ & 248.27 & 271.24 & 237.22 & 261.37 & 161.64 \\
\hline MP steam produced, $\mathrm{kg} / \mathrm{s}$ & 25.99 & 60.48 & 38.19 & 62.52 & 0.00 \\
\hline LP steam produced, $\mathrm{kg} / \mathrm{s}$ & 7.79 & 35.74 & 15.63 & 19.16 & 55.66 \\
\hline $\mathrm{HP}$ steam at turbine inlet, $\mathrm{kg} / \mathrm{s}$ & 248.27 & 271.24 & 237.22 & 261.37 & 161.64 \\
\hline MP steam into gasifier, $\mathrm{kg} / \mathrm{s}$ & 7.24 & 7.73 & 7.71 & 7.73 & 7.73 \\
\hline MP steam bleed into WGS, $\mathrm{kg} / \mathrm{s}$ & 0.00 & 153.66 & 71.25 & 117.65 & 28.97 \\
\hline MP steam bleed into GT, $\mathrm{kg} / \mathrm{s}$ & 21.39 & 0.00 & 0.00 & 0.00 & 0.00 \\
\hline MP steam at turbine inlet, $\mathrm{kg} / \mathrm{s}$ & 243.17 & 171.31 & 195.75 & 195.95 & 152.31 \\
\hline LP steam at turbine inlet, $\mathrm{kg} / \mathrm{s}$ & 250.97 & 184.62 & 211.39 & 215.10 & 207.98 \\
\hline Net HRSC electric power, MW & 359.84 & 281.08 & 300.72 & 310.85 & 254.34 \\
\hline
\end{tabular}

Table 4

Plant performance, with breakdown of power consumption by unit.

\begin{tabular}{|c|c|c|c|c|c|}
\hline Plant performance & $S V$ & $S C$ & $S E$ & $S N$ & $Q C$ \\
\hline \multicolumn{6}{|l|}{ Elec. power consumption, MW: } \\
\hline Coal handling, gasifier & 17.30 & 18.47 & 18.42 & 18.42 & 18.47 \\
\hline ASU, $\mathrm{O}_{2} \& \mathrm{~N}_{2}$ compr., pumps & 144.55 & 123.03 & 128.69 & 128.69 & 123.65 \\
\hline AGR, Claus, SCOT units & 1.04 & 19.69 & 19.75 & 19.75 & 19.69 \\
\hline $\mathrm{CO}_{2}$ drying \& compression & 0.00 & 35.08 & 35.18 & 35.18 & 35.08 \\
\hline Auxiliary elec. power, $M W$ & 162.89 & 196.27 & 202.04 & 202.04 & 196.89 \\
\hline \multicolumn{6}{|l|}{ Elec. power production, MW: } \\
\hline GT net power $(2 \times$ GE 9 FB $)$ & 627.60 & 592.92 & 593.92 & 593.92 & 592.92 \\
\hline HRSC net elec. power & 359.76 & 279.57 & 300.58 & 310.86 & 253.91 \\
\hline Net electric power, MW & 824.47 & 676.21 & 692.46 & 702.60 & 649.94 \\
\hline Coal input, MW (LHV basis) & 1729.7 & 1846.7 & 1841.6 & 1841.6 & 1846.7 \\
\hline $\begin{array}{l}\text { Net electric efficiency (LHV } \\
\quad \text { basis), \% }\end{array}$ & 47.66 & 36.62 & 37.60 & 38.15 & 35.19 \\
\hline $\begin{array}{l}\text { Overall carbon capture } \\
\text { level, \% }\end{array}$ & 0.00 & 93.09 & 93.09 & 93.09 & 93.09 \\
\hline $\begin{array}{l}\text { Specific } \mathrm{CO}_{2} \text { emissions, } \\
\text { g/kWh }\end{array}$ & 667.75 & 52.01 & 51.70 & 51.07 & 54.81 \\
\hline
\end{tabular}

steam/gas temperatures and syngas cooler integration). Our results predict that such high efficiencies are possible using well optimized, commercial technologies.

\subsection{SC, SE, QC: $\mathrm{CO}_{2}$ capture cases}

These plants share the same $98 \%$ CO conversion efficiency and AGR, and thus achieve the same overall degree of carbon capture, i.e., 93.1\%. The difference between them are the syngas humidification process and the WGS layout.

\subsection{SV vs. SC: $\mathrm{CO}_{2}$ capture penalty}

The more than 23\% drop in LHV efficiency between cases $\boldsymbol{S V}$ and $\boldsymbol{S C}$ reflects the well-known losses via WGS (steam consumption and reduction in syngas heating value) and $\mathrm{CO}_{2}$ compression. (Note that the $\mathrm{N}_{2}$ compression power for $\mathrm{NO}_{x}$ control is smaller in case SC.) A primary goal of this work is to reduce this efficiency loss by novel syngas humidification schemes.

\subsection{SC vs. QC: partial water quench}

As seen in Table 3, the partial water quench amply fulfills its design goal of reducing the steam needed for syngas shifting; the WGS unit in $\mathbf{Q C}$ consumes less than 1/5 of the MP steam required by $\boldsymbol{S C}$. However, the loss of syngas coolers exacts a thermodynamic toll; the overall efficiency of case $\mathbf{Q C}$ is $3.9 \%$ (or 1.4 percentage points, pp) less than $S C$. The reason is that quenching $1400^{\circ} \mathrm{C}$ syngas with hot water is the most irreversible method (in the plants studied here) of increasing syngas humidification, and consequently case $\boldsymbol{Q C}$ has the lowest efficiency of all cases, 35.2\%. In contrast, case $\boldsymbol{S C}$ employs the least irreversible method, steam injection.

At first, the 3.9\% drop in efficiency from case $\boldsymbol{S C}$ to $\mathbf{Q C}$ seems surprisingly small in light of the $40 \%$ reduction in HP steam available to the steam turbine (Table 3 ). The reason is that the mass flow rate of steam is only one of three important factors governing the steam turbine's mechanical power, equal to the integral of $q * \eta * v * d p$ along the expansion (where $q$ is the mass flow rate, $v$ is the steam specific volume, $\eta$ is the polytropic efficiency, and $d p$ the infinitesimal pressure drop). Despite the higher mass flow rate of HP steam in case $\boldsymbol{S C}$, the product $v * \eta$ is lower because $v$ is relatively small (HP section inlet: $v=0.0243 \mathrm{~m}^{3} / \mathrm{kg}$, MP section inlet: $v=0.0937 \mathrm{~m}^{3} / \mathrm{kg}$, LP section inlet: $v=0.522 \mathrm{~m}^{3}$ / $\mathrm{kg}$ ) and the polytropic efficiency $\eta$ is lower because of the smaller ratio of blade height to diameter. Thus, the fact that the quench plant expands $12.6 \%$ more low pressure (LP) steam than in case SC (and only $11 \%$ less MP steam) goes a long way toward mitigating the effects of reduced HP steam.

\subsection{SC vs. SE: ECN WGS}

The ECN design reduces the WGS steam requirement by $54 \%$ (vs. 81\% in QC). By humidifying syngas with both steam and water, case $\boldsymbol{S E}$ would seem to be - exergetically - an intermediate between $\boldsymbol{S C}$ and $\boldsymbol{Q C}$. However, its $37.6 \%$ overall efficiency is $2.7 \%$ (1 pp) higher than the conventional WGS case, i.e., $\boldsymbol{S C}$. The comparison between the steam cycles in $\boldsymbol{S E}$ and $\boldsymbol{S C}$ mirrors the previous discussion of $\boldsymbol{Q C}$ vs. SC. Although $\boldsymbol{S E}$ generates $12.5 \%$ less HP steam than $S C$, it expands $14 \%$ more MP steam and $14.5 \%$ more LP steam. Not surprisingly, its steam turbine produces $20 \mathrm{MW}$ (7.5\%) more power. This discrepancy is the most important factor underlying the difference in overall plant efficiency between the two cases. $^{7}$

To investigate in detail why the bottoming cycle of $\boldsymbol{S} \boldsymbol{E}$ generates more power than that of $\boldsymbol{S C}$, we use a detailed exergy analysis. As observed by Kunze et al. [23], a structured exergy analysis is a powerful tool for identifying subsystems, components and processes with the highest potential for improvements in efficiency. For example, Kunze et al. compute unit-level exergy losses throughout an IGCC, and identify those with the largest exergy loss: the gas turbine, gasifier, AGR unit and WGS section. However,

\footnotetext{
7 The difference in overall net power is smaller than that of the HRSC power because of the difference in the electric consumption of the $\mathrm{N}_{2}$ compressor for syngas dilution. Indeed the syngas saturation scheme varies between the two plants; case $\boldsymbol{S C}$ can recover more low temperature heat (because of its higher syngas dew point) and heat up the saturator water up to $170^{\circ} \mathrm{C}$, while case $\boldsymbol{S E}$ can reach only $160{ }^{\circ} \mathrm{C}$ (using higher temperature heat). As a consequence, case $\boldsymbol{S C}$ needs more $\mathrm{N}_{2}$ (thus more compression power) as a diluent to meet the stoichiometric flame temperature required for $\mathrm{NO}_{x}$ control.
} 
Table 5

Comparison of exergy losses (expressed in MW) within the WGS unit, syngas cooling, and steam turbine. The difference in the total exergy loss equals the difference in the net power of the two HRSCs.

\begin{tabular}{lllll}
\hline \multirow{2}{*}{ Plant section } & Exergy losses, MW & & & \\
\cline { 2 - 5 } WGS unit & Process & $\boldsymbol{S C}$ & $\boldsymbol{S E}$ & Difference \\
\hline & Mix syngas + water & 23.12 & 35.85 & -12.74 \\
& WGS reaction & 32.90 & 26.64 & 6.26 \\
& Heat transfer & 2.20 & 0.00 & 2.20 \\
& Total loss in WGS & 58.21 & 62.50 & -4.28 \\
& unit & & & \\
LT syngas cooling & Heat transfer & 16.69 & 5.37 & 11.32 \\
section & Cooling: $140{ }^{\circ} \mathrm{C}$ to & 37.47 & 23.10 & 14.37 \\
Overall & $38^{\circ} \mathrm{C}$ & & & \\
& Total exergy loss & 112.37 & 90.97 & 21.41 \\
\hline
\end{tabular}

a unit-level exergy analysis is not sufficiently detailed to explicate the fundamental differences between the WGS designs for cases $\boldsymbol{S C}$ and $\boldsymbol{S E}$. Thus, we employ a more detailed analysis that computes exergy losses for individual physical/chemical phenomena (e.g., chemical reaction, heat transfer, mixing/separation process, pressure drop, etc.) and basic components (heat exchanger, mixer, reactor, turbine, compressor, etc). The ExerCom routine for Aspen Plus [24] is used to calculate the physical exergy (i.e., the amount of reversible work which can be obtained by cooling and expanding a given stream to the environmental/reference pressure and temperature) and the chemical exergy of streams (i.e., the amount of reversible work which can be obtained by chemically converting, cooling and expanding a given stream up to the environmental pressure, temperature and composition) with reference to the environmental conditions defined by Szargut et al. in [25].

The primary differences between the HRSCs of cases $\boldsymbol{S C}$ and $\boldsymbol{S E}$ lie in the WGS unit and LT syngas cooling; the remaining units (i.e., HT syngas coolers, reboilers in the AGR, gas and steam turbines, and HRSGs) are essentially identical. Therefore, within this comparative approach, it is possible to limit the detailed exergy analysis to the processes and components of the WGS unit and LT syngas cooling section (see Table 5). Table 5 indicates that the process of mixing syngas with water in the ECN WGS is about 13 MW more dissipative than mixing syngas with steam in the conventional WGS. However, because the ECN arrangement requires much less water overall, that loss is more than repaid in the LT syngas cooling section where less latent heat of condensing water is wasted (exergetically). ${ }^{8}$ As a proof of accuracy and correctness of our comparative approach, it is worth noting that the comparative exergy analysis accounts almost exactly for the difference in HRSC power between the two cases.

If we employ the "aggressive" set of HRSC parameters rather than the default "conservative" assumptions, the gain in plant efficiency offered by case $\boldsymbol{S E}$ is markedly reduced, from $2.7 \%$ to only $1 \%$ $(0.37 \mathrm{pp})$ because the improved bottoming cycle benefits case $\boldsymbol{S C}$ more than $\boldsymbol{S} \boldsymbol{E}$. Case $\boldsymbol{S C}$ makes more LT heat because it adds more $\mathrm{H}_{2} \mathrm{O}$ to the syngas, and efficient recovery of this heat is critical to high overall efficiency. The LP pressure level is particularly important ${ }^{9}$ in this regard; at $p_{\mathrm{LP}}=3.7$ bar, the exergy loss during LT cooling drops from 17 to $9 \mathrm{MW}$ because, instead of inefficient economizing at very low temperatures, LP steam now can be evaporated using LT heat (below the dew point, $190-170{ }^{\circ} \mathrm{C}$ ).

It is worth noting that our calculation of the efficiency gain offered by case $\boldsymbol{S E}$ is smaller than that calculated in a recent study by

\footnotetext{
${ }^{8}$ No power can be produced by cooling syngas from 140 to $25^{\circ} \mathrm{C}$ because the plants already have a large surplus of unrecoverable low temperature heat.

${ }^{9}$ Reducing the lower limit of $p_{\mathrm{LP}}$ appears to be significantly more beneficial than raising the upper limit on $p_{\mathrm{HP}}$ to $170 \mathrm{bar}$
}

ECN [5]. This appears to have two causes. First, compared with Ref. [5], this work examines relatively high (98\%) CO conversion efficiencies, which tend to reduce the advantages of the ECN design. Second, we employ here a new methodology $[12,13]$ for optimizing the configuration of each plant's heat integration/bottoming cycle (including pressure levels), assuming modern greenfield steam cycle design. As we have shown above, the relative performance of the two systems depends critically upon the details of the HRSC.

\subsection{SN vs. SE: comparison between advanced WGS layouts}

The exergy analysis of the WGS unit shows that reducing the moisture content of the shifted syngas lessens the carbon capture penalty by lowering the exergy loss in the LT cooling section. This observation is fundamental to optimize the WGS unit in case $\boldsymbol{S N}$ : the free variables of the design can be adjusted to minimize the water content at the exit of the last WGS reactor (i.e. molar flow of $\mathrm{H}_{2} \mathrm{O}$ in the shifted syngas), or equivalently, the steam/water consumption (i.e. molar flow of $\mathrm{H}_{2} \mathrm{O}$ injected in the WGS unit). The optimization has been carried out via the Sequential Quadratic Programming algorithm of Lang and Biegler [26] which is available in Aspen Plus. The resulting optimized layout is surprisingly simple: one only steam injection and two only feed gas split flows are necessary to achieve optimum performance (see Fig. 6). Compared with ECN case $\boldsymbol{S E}$, the total water consumption is $9.4 \%$ lower and the LHV electric efficiency is 0.55 pp higher). A sensitivity analysis around the optimum configuration reveals that the $\boldsymbol{S N}$ plant efficiency decreases by only $0.08 \mathrm{pp}$ if employing three reactors instead of four (due to the absence of one reactor, this layout needs $6 \%$ more steam but keeps the same layout shown in Fig. 6). Further reducing the number of reactors from three to two leads to a more significant loss of efficiency; indeed the optimized $S N$ configuration with two reactors is exactly equal to the conventional WGS layout (i.e. all the feed gas enters the first reactor), case $\boldsymbol{S C}$.

Replacing the deleterious ECN water quench with the steam injection has multiple effects: 1 . it reduces the water-syngas mixing irreversibility, 2. it increases the number of degrees of freedom leaving room for process optimization, 3 . it reduces the total water consumption, and 4 . it raises the plant efficiency by $0.55 \mathrm{pp}$. However this gain of efficiency is achieved by employing an optimized heat recovery steam cycle that is fully integrated with the power island and (additional) syngas coolers. Hence, while an economic comparison between cases $\boldsymbol{S N}$ and $\boldsymbol{S E}$ has not been attempted here, we suspect that the gain in efficiency is insufficient to justify the increased capital costs (of the required syngas coolers and the larger and more complex HRSC) and operating difficulties (start-up, shut-down and off-design operation) due to the integration between the steam generator and the WGS coolers. For these reasons, although the $\boldsymbol{S N}$ configuration is more efficient, the ECN WGS layout appears to achieve a better balance between capital cost, plant complexity and energy efficiency.

\section{Comparative plant economics}

Economic parameters used to estimate the costs of producing electricity are given in Table 6. Our costing analysis uses the EPRI TAG methodology [27], and is kept simple and transparent to facilitate revision by readers wishing to use different economic assumptions. The assumed coal price, $1.71 \$ / G J$ (LHV basis), was adopted from Ref. [1]. Interest during construction (IDC) is taken to be $12.3 \%$ of overnight capital (TCP), based on a 4 -year construction schedule with equal, annual payments, and a real discount rate of $7.8 \% / y r$. The 30 year levelized capital charge rate (CCR), applied to the total plant investment (TPI = TPC + IDC), is assumed to 


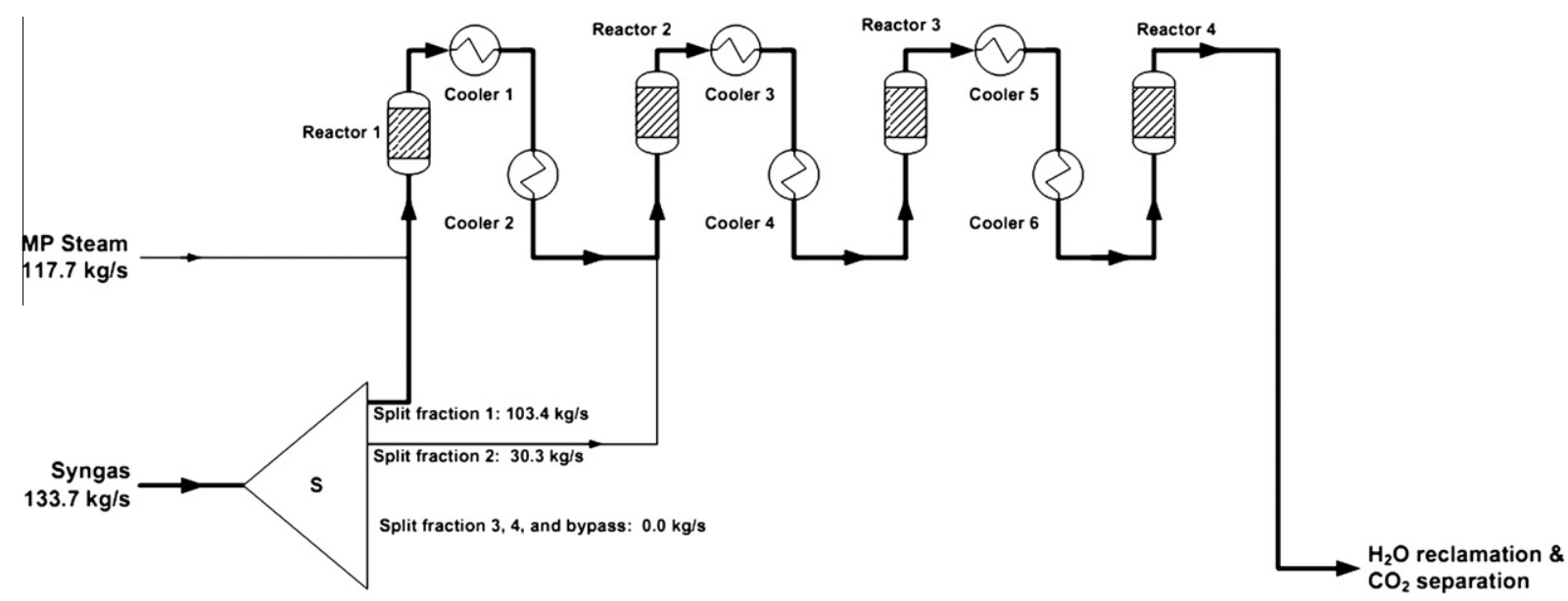

Fig. 6. Optimized layout of the proposed advanced WGS unit employed in option SN.

Table 6

Economic assumptions employed here.

\begin{tabular}{ll}
\hline Coal price [1], \$/GJ HHV & 1.71 \\
Capacity factor, \% & 85.0 \\
Capital charge rate (CCR) [12], \%/year & 15.0 \\
Interest during construction (IDC) [12], \% of overnight capital & 12.3 \\
Operation \& maintenance (O\&M), \% of overnight capital/yr & 4.0 \\
$\mathrm{CO}_{2}$ transport + storage costs [13], \$/tonne of $\mathrm{CO}_{2}$ & 7.1 \\
U.S. dollars valued in year & 2008 \\
& (mid-year)
\end{tabular}

be $15 \% / y r .{ }^{10}$ Operation and maintenance (O\&M) costs are fixed at $4 \%$ of TPC per year. The plant capacity factor is assumed to be $85 \%$. At these plant sizes, $\mathrm{CO}_{2}$ removal rates are high (566.1 tonnes/hr in case SC), and so transport and storage costs are potentially quite modest, only $7.1 \$$ /tonne $\mathrm{CO}_{2}$ here. ${ }^{11}$ Our model for estimating the capital costs of each major plant component is derived from the detailed capital cost data for Shell IGCC plants given in a May 2007 study by NETL [1]. Costs are escalated to mid-2008 US dollars using the Chemical Engineering Plant Cost Index [29,30]. The total plant costs (TPC), or "overnight construction costs", given in Table 7 for each case, includes engineering and overhead, general facilities, balance of plant (BOP), and both process and project contingencies (3.2 and $17 \%$ of the bare erected costs, respectively).

A comparison of capital costs between the standard and novel plants with $\mathrm{CO}_{2}$ capture requires a careful assessment of the cost of various heat exchangers, both standard and costly syngas coolers. This work attempts only to provide a rough estimate of these costs in order to give the reader an idea of the economic impact of such changes, and the ultimate effect on the levelized cost of electricity (LCOE). The costs of syngas coolers, $\sim 400 \$ / \mathrm{kW}$ (exchanged thermal power basis), in case $\mathbf{Q C}$ is derived from NETL [1]. With regard to the cost of less exotic heat exchangers used in the WGS unit, the capital cost of case $\boldsymbol{S} \boldsymbol{E}$ was reduced relative to case $\boldsymbol{S C}$ based on $165 \mathrm{MW}$ less WGS heat exchanged, assuming

\footnotetext{
${ }^{10}$ CCR is calculated using EPRI TAG methodology [27] with the modified accelerated capital recovery system (MACRS) for tax depreciation, assuming an inflation rate of $2 \% / y e a r$, a real discount rate-assumed equal to the weighted, after-tax cost of capital-of 7.8\%/year (based on real costs for debt and equity capital of 4.4 and $14.0 \%$ / year, respectively, and a capital structure consisting of $55 \%$ debt and $45 \%$ equity), a book life of 30 years with no plant salvage value, a tax life of 20 years, a federal + state income tax rate of $38.2 \%$ year, and annual owners costs of $5.5 \%$ of TPI. Note that CCR includes property taxes and insurance in the amount of $2 \%$ of total cash expended (or $1.71 \%$ of TPI)

11 Estimated costs for $\mathrm{CO}_{2} \mathrm{~T}+\mathrm{S}$ are based on a $100 \mathrm{~km}$ pipeline, aquifer depth of $2 \mathrm{~km}, \mathrm{CO}_{2}$ injectivity of 2500 tonne/day per well, and a 19\%/yr capital charge rate [28].
}

an installed capital cost of $100 \$ / \mathrm{kW}$ (exchanged thermal power basis). The cost of additional catalyst in the ECN WGS system (estimated in Ref. [5] to be about 1.5 times greater than that used in conventional WGS units) was neglected.

\subsection{Cost of electricity}

The levelized cost of electricity (LCOE) for each plant is given in Table 8 for two prices on $\mathrm{CO}_{2}$ emissions: zero and $45.6 \$ /$ tonne, the lowest "crossover" carbon price, i.e. the smallest $\mathrm{CO}_{2}$ emissions price at which the LCOE for the most advantageous $\mathrm{CO}_{2}$ capture plant (in this case $\boldsymbol{S E}$ ) equals that of $\mathrm{CO}_{2}$ venting case $\boldsymbol{S V}$.

At a $\mathrm{CO}_{2}$ emissions price of $45.6 \$ /$ tonne, despite the lower efficiency caused by lack of syngas coolers, the LCOE for case $\mathbf{Q C}$ is $0.9 \%$ less than that of $\boldsymbol{S C}$. This is because the TPC is lower by $6.5 \%$ than in case $\boldsymbol{S C}$. We also might expect a higher availability for the partial water quench plants due to lack of syngas cooler fouling, leakage, and corrosion.

The ECN WGS also yields greater efficiency and lower cost (TPC is reduced by about $1 \%$ ) relative to the conventional unit, causing a $3.1 \%$ reduction in LCOE of case $\boldsymbol{S E}$ relative to $\boldsymbol{S C}$. (Using the "aggressive" HRSC assumptions, however, the reduction in LCOE is roughly halved to $1.6 \%$, as case $\boldsymbol{S C}$ benefits more from the increased bottoming cycle efficiency.) The plant integration between the WGS and steam cycle is notably simplified, promising improved reliability and ease of plant operation.

\section{Conclusion}

This work has investigated two methods of humidifying syngas in a dry feed coal IGCC in order to make it more efficient when employing WGS and a high level of $\mathrm{CO}_{2}$ capture. Compared to the reference case with gas quench and high temperature syngas coolers, the partial water quench is simpler, less expensive, but less efficient ( $-1.4 \mathrm{pp}$ LHV efficiency); however, it offers the potential of appreciable economic benefits ( $-6.5 \%$ total plant cost and $-0.9 \%$ levelized cost of electricity). On the other hand, keeping the gas quench system with high temperature syngas coolers, it is thermodynamically advantageous to employ advanced WGS layouts with low steam and water consumption: the ECN configuration gains $1 \mathrm{pp}$ while the optimized WGS layout gains $1.5 \mathrm{pp}$ of LHV efficiency.

Among these innovative configurations, the ECN WGS coupled with the Shell gas quench system appears to be the most attractive one because brings increased efficiency, a significantly reduced WGS steam cycle integration and also improved economics $(-1 \%$ 
Table 7

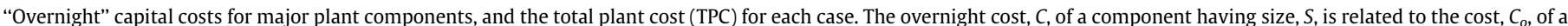

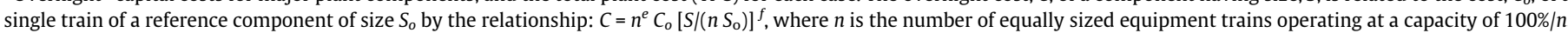
$f$ is the cost scaling factor, and $e=0.9$ is the cost scaling exponent for multiple trains of equipment.

\begin{tabular}{|c|c|c|c|c|c|c|c|c|c|c|c|c|c|}
\hline \multirow[t]{2}{*}{ Plant component } & \multirow[t]{2}{*}{ Scaling parameter } & \multirow[t]{2}{*}{ So } & \multirow[t]{2}{*}{$n$} & \multirow[t]{2}{*}{$f$} & \multirow{2}{*}{$\begin{array}{l}\text { Co } \\
(\mathrm{M} \$)\end{array}$} & \multicolumn{2}{|l|}{ SV } & \multicolumn{2}{|l|}{$S C$} & \multicolumn{2}{|l|}{$\underline{S E}$} & \multicolumn{2}{|l|}{$\underline{Q C}$} \\
\hline & & & & & & $S$ & $\begin{array}{l}\mathrm{C} \\
(\mathrm{M} \$)\end{array}$ & $\mathrm{S}$ & $\begin{array}{l}\mathrm{C} \\
(\mathrm{M} \$)\end{array}$ & $\mathrm{S}$ & $\begin{array}{l}\mathrm{C} \\
(\mathrm{M} \$)\end{array}$ & $\mathrm{S}$ & $\begin{array}{l}\mathrm{C} \\
(\mathrm{M} \$)\end{array}$ \\
\hline Coal + sorbent handling & AR coal, tonne/day & 5447 & 1 & 0.67 & 40.4 & 5776 & 42.0 & 6167 & 43.9 & 6150 & 43.8 & 6167 & 43.9 \\
\hline Coal prep \& feeding & AR coal, tonne/day & 2464 & 2 & 0.67 & 101.6 & 5776 & 211.0 & 6167 & 220.4 & 6150 & 220.0 & 6167 & 220.4 \\
\hline Ash handling & Coal ash, tonne/day & 477.8 & 1 & 0.67 & 38.1 & 705 & 49.4 & 752.3 & 51.6 & 750 & 51.5 & 752.3 & 51.6 \\
\hline ASU, $\mathrm{O}_{2} \& \mathrm{~N}_{2}$ compressor & Pure $\mathrm{O}_{2}$, tonne/day & 2035 & 2 & 0.50 & 106.7 & 4013 & 197.7 & 4284 & 204.3 & 4272 & 204.0 & 4284 & 204.3 \\
\hline Std. gasifier, SG coolers & AR coal, MW LHV & 737.4 & 2 & 0.67 & 178.1 & 1730 & 369.8 & 1847 & 386.3 & 1842 & 385.6 & - & - \\
\hline Partial quench gasifier & AR coal, MW LHV & 770.9 & 2 & 0.67 & 139.5 & - & - & - & - & - & - & 1847 & 293.8 \\
\hline LT heat recovery, saturator & AR coal, MW LHV & 737.4 & 2 & 0.67 & 17.3 & 1730 & 36.0 & 1847 & 37.6 & 1842 & 37.5 & 1847 & 37.6 \\
\hline COS hydrolysis & AR coal, MW LHV & 797.7 & 2 & 0.67 & 4.7 & 1730 & 9.2 & - & - & - & - & - & - \\
\hline Water-gas shift reactors & AR coal, MW LHV & 815.2 & 2 & 0.67 & 9.3 & - & - & 1847 & 6.1 & 1842 & $2.3^{*}$ & 1847 & 18.9 \\
\hline Gas cleanup BOP & AR coal, MW LHV & 815.2 & 2 & 0.67 & 6.1 & 1730 & 11.8 & 1847 & 12.4 & 1842 & 12.3 & 1847 & 12.4 \\
\hline AGR $\left(\mathrm{H}_{2} \mathrm{~S}\right.$ capture only) & S input, tonne/day & 66.8 & 2 & 0.67 & 49.6 & 50 & 47.7 & 53.1 & 49.9 & 53.0 & 49.8 & 53.1 & 49.9 \\
\hline 2nd stage $\mathrm{CO}_{2}$ capture & $\begin{array}{l}\mathrm{CO}_{2} \text { captured, tonne/ } \\
\mathrm{hr}\end{array}$ & 234.3 & 2 & 0.67 & 55.2 & - & - & 566.1 & 117.0 & 564.6 & 116.8 & 566.1 & 117.0 \\
\hline Claus plant & S input, tonne/day & 136.5 & 1 & 0.67 & 37.6 & 50 & 19.1 & 53.1 & 19.9 & 53.0 & 19.9 & 53.1 & 19.9 \\
\hline $\mathrm{CO}_{2}$ compression \& drying & $\begin{array}{l}\text { Compressor pwr, } \\
\mathrm{MW}_{\mathrm{e}}\end{array}$ & 27.4 & 1 & 0.67 & 43.0 & - & - & 35.1 & 50.8 & 35 & 50.9 & 35.1 & 50.8 \\
\hline General Electric 9FB GT & - & - & 2 & - & 68.5 & - & 127.8 & - & 127.8 & - & 127.8 & - & 127.8 \\
\hline HRSG, ductwork, stack & GT net power, $\mathrm{MW}_{\mathrm{e}}$ & 232.0 & 2 & 0.67 & 33.8 & 628 & 77.2 & 592.9 & 74.3 & 594 & 74.4 & 592.9 & 74.3 \\
\hline ST, condenser, auxiliaries & ST gross power, $\mathrm{MW}_{\mathrm{e}}$ & 274.7 & 1 & 0.67 & 74.0 & 360 & 88.6 & 279.6 & 74.9 & 300.6 & 78.6 & 253.9 & 70.2 \\
\hline Balance of plant & $15.5 \%$ of plant cost & & & & & & 235.3 & & 269.9 & & 269.6 & & 254.5 \\
\hline Total Plant Cost (TPC) & & & & & & & 1523 & & 1747 & & 1745 & & 1647 \\
\hline $\begin{array}{l}\text { Specific Total Plant Cost (\$/kW of electric } \\
\text { power) }\end{array}$ & & & & & & & 1847 & & 2584 & & 2520 & & 2535 \\
\hline
\end{tabular}

* Cost reduced by 16.5 M\$ because of reduction in $165 \mathrm{MW}$ of heat exchangers.

Table 8

Levelized cost of electricity for each case.

\begin{tabular}{lllll}
\hline Cost component, mid-2008 \$/MWh & SV & SC & SE & QC \\
\hline Installed capital (at 15\% of TPI) & 41.7 & 58.8 & 56.9 & 57.2 \\
O\&M (at 4\% of TPC per yr) & 9.9 & 14.0 & 13.5 & 13.6 \\
Coal (at 1.71 \$/GJ, HHV) & 13.5 & 17.6 & 17.1 & 18.3 \\
$\mathrm{CO}_{2}$ disposal (at 7.1 \$/tonne) & 0.0 & 5.8 & 5.7 & 6.0 \\
$\mathrm{LCOE}$ (no carbon price) & 65.0 & 96.2 & 93.1 & 95.1 \\
$\mathrm{CO}_{2}$ emissions (at 45.6 \$/tonne) & 30.5 & 2.4 & 2.4 & 2.5 \\
LCOE with $\mathrm{CO}_{2}$ price (46.4 \$/tonne) & 95.5 & 98.5 & 95.5 & 97.6 \\
Cost of avoided $\mathrm{CO}_{2}, \$$ tonne of $\mathrm{CO}_{2}$ & - & 50.5 & 45.6 & 49.0 \\
\hline
\end{tabular}

total plant cost and $-3.1 \%$ levelized cost of electricity compared to the reference case).

\section{Acknowledgments}

We are grateful to Prof. Paolo Chiesa for allowing us use his GT model and for providing the calibration of the GE 9FB. Thanks also to LEAP (Laboratorio Energia Ambiente Piacenza), Politecnico di Milano sede di Piacenza, Princeton Environmental Institute (Prof. R. Socolow) and ECN for funding and hosting Emanuele Martelli during this research.

\section{Appendix A}

Table A1.

Table A1

Technical assumptions used in calculations of plant performance.

Shell gasification island

Dried coal moisture content (wt\%)

Syngas for drying (\% of total flow)

Gasification pressure (bar)

$\mathrm{H}_{2} \mathrm{O} / \mathrm{O}_{2}$ molar ratio (steam as moderator)

1.0

38.5

0.266
Table A1 (continued)

$\begin{array}{ll}\text { Gasification temperature } & 1372 \\ \text { Carbon conversion (with fly ash recycle) } & 99.79 \\ \mathrm{O}_{2} \text { purity (\% molar fraction) } & 95 \\ \mathrm{HP} \mathrm{N}_{2} \text { for pressurization/coal mass flow rate (wt ratio) } & 0.3193 \\ \mathrm{LP} \mathrm{N}_{2} \text { for coal transport/coal mass flow rate (wt ratio) } & 0.1244 \\ \mathrm{HP} \mathrm{N}_{2} \text { into syngas/dried coal (wt ratio) } & 0.103 \\ \text { Maximum oxidant temperature }\left({ }^{\circ} \mathrm{C}\right) & 100 \\ \text { Syngas coolers: pinch point temp. diff. HT/LT coolers (K) } & 50 / 15 \\ \text { Steam/CO value in the WGS reactor } & 2.5 \\ \text { Heat loss from heat exchangers (\%) } & 0.5 \\ \text { Heat to membrane wall (\% coal LHV thermal power) } & 1.50 \\ \text { Syngas coolers \& wet scrubber pressure drop (\%) } & 4.00 \\ \text { Electricity use: coal handling + water system (\% of coal LHV) } & 1.00 \\ \text { Syngas treatment and conditioning line } & \\ \text { Heat exchangers pressure drops - gas side (\%) } & 0.05 \\ \text { Heat exchanger heat losses (\%) } & 0.5 \\ \text { Quench water pump hydraulic efficiency } & 0.85 \\ \text { Quench water pump elec. } \times \text { mechanical efficiency } & 0.9 \\ \text { Saturator pump hydraulic efficiency } & 0.8 \\ \text { Saturator pump electrical } \times \text { mechanical efficiency } & 0.9\end{array}$

Acid gas removal (AGR) unit

Selexol for selective removal of $\mathrm{CO}_{2} \& \mathrm{H}_{2} \mathrm{~S}$, data from [1]:

LT heat for stripping (MJ per $\mathrm{kg}$ of stripped $\mathrm{H}_{2} \mathrm{~S}$ )

$\mathrm{H}_{2}$ co-absorbed (\%)

CO co-absorbed (\%)

Specific electricity consumption (kJ per kg of abs. CO2)

Sulfinol-M for removal of $\mathrm{H}_{2} \mathrm{~S}$, data from [1]:

LT heat for stripping (MJ per kg of stripped $\mathrm{H}_{2} \mathrm{~S}$ )

Specific electricity consumption (kJ per kg of syngas)

$\mathrm{CO}$ co-absorbed (\%)

$\mathrm{H}_{2}$ co-absorbed (\%)

95

0.1244

100

$50 / 15$

1.50

4.00

1.00

0.05

0.5

0.8
0.9

Water-gas shift (WGS) unit

HT/LT WGS reactor approach temperatures K)

$\begin{array}{ll}\text { HT/LT WGS syngas input temperatures }\left({ }^{\circ} \mathrm{C}\right) & 250 / 250\end{array}$

$\mathrm{CO}_{2}$ compression and drying

Specific electricity use (kJ per kg of $\mathrm{CO}_{2}$ ), data from [1] 222.7

Air separation unit (ASU)

Air compressor (axial), polytropic efficiency

Pressure of $\mathrm{O}_{2}$ and $\mathrm{N}_{2}$ delivered by ASU (bara)
44.7

0.533

0.0044

125

13.4

9.36

0.265

0.268

0.86

1.05 
Table A1 (continued)

\begin{tabular}{|c|c|}
\hline Excess air & 0.06 \\
\hline Compressor electrical $\times$ mechanical efficiency & 0.92 \\
\hline $\mathrm{O}_{2}$ compressor ( $3 \mathrm{ICs}$ ), 4 radial stages, average $\eta_{\text {polytropic }}$ & 0.845 \\
\hline LP $N_{2}$ compressor ( $1 \mathrm{IC}$ ), 2 radial stages, average $\eta_{\text {polytropic }}$ & 0.858 \\
\hline HP $\mathrm{N}_{2}$ compressor ( 2 ICs), 3 radial stages, average $\eta_{\text {polytropic }}$ & 0.79 \\
\hline Dilution $\mathrm{N}_{2}$ compressor (axial machine, 1 IC), avg. $\eta_{\text {polytropic }}$ & 0.887 \\
\hline Intercooler exit temperature $\left({ }^{\circ} \mathrm{C}\right)$ & 45 \\
\hline \multicolumn{2}{|l|}{$\begin{array}{l}\text { Power island } \\
\text { ( } 2 \text { GE 9FB GTs }+2 \text { HRSGs }+1 \text { steam turbine) } \\
\text { HRSC, triple pressure levels with RH }\end{array}$} \\
\hline Approach temperature: Steam SH - Hot flue gas (K) & 25 \\
\hline Min. pinch points/sub-cooling temp. diff. in HRSG (K) & $8 / 3$ \\
\hline Pumps: hydraulic efficiency & 0.84 \\
\hline Pumps: electrical $\times$ organic efficiency & 0.9 \\
\hline Maximum steam pressure (for the HP level), bar & $140\left(170^{*}\right)$ \\
\hline Minimum steam pressure (for the LP level), bar & $5\left(3^{*}\right)$ \\
\hline Steam turbine mechanical efficiency & 0.98 \\
\hline Steam turbine generator electrical efficiency & 0.99 \\
\hline Economizers: pressure losses (\%) & 25 \\
\hline Superheater and reheater pressure losses (\%) & 8 \\
\hline Condenser pressure (bar) & 0.05 \\
\hline \multicolumn{2}{|l|}{ Other units } \\
\hline Sour water stripper, LP steam requirement, $\mathrm{kJ} / \mathrm{kg}$ coal & 84.0 \\
\hline Electricity for cooling components (\% of rejected heat) & 0.5 \\
\hline
\end{tabular}

* "Aggressive" HRSC parameter assumptions.

\section{References}

[1] NETL (National Energy Technology Laboratory). Cost and performance comparison baseline for fossil energy power plants. Bituminous coal and natural gas to electricity, vol. 1. DOE/NETL-401/053106 Final Report; May 2007.

[2] Booras G. Economic assessment of advanced coal-based power plants with $\mathrm{CO}_{2}$ capture. MIT carbon sequestration forum IX, advancing $\mathrm{CO}_{2}$ Capture. Cambridge, MA; September 16, 2008.

[3] BP (British Petroleum). BP statistical review of world energy; 2008. <http:// www.bp.com/>.

[4] Shell Internationale Research Maatschappij B.V. WIPO/PCT. Method and System for Producing Synthesis Gas. Patent Application No. WO 2006 117355 A1, World Intellectual Property Organization; 9 November 2006.

[5] Carbo MC, Boon J, Jansen D, van Dijk HAJ, Dijkstra JW, van den Brink RW, et al Steam demand reduction of water-gas shift reaction in IGCC power plants with pre-combustion $\mathrm{CO}_{2}$ capture. Int J Greenhouse Gas Control 2009;3:712-9.

[6] Aspen Tech; 2011. <www.aspentech.com>.

[7] Prefeasibility study of IGCC in China using shell coal gasification. Unpublished report; courtesy of Prof. Li Zheng. Tsinghua University. Beijing, China; 2001.

[8] DePriest W, Van Laar J. (Sargent \& Lundy). Engineering evaluation of prenflobased integrated-gasification-combined-cycle (IGCC) power plant designs EPRI (Electric Power Research Institute) report TR-101609, Final Report; November 1992.
[9] IEA (International Energy Agency). Potential for improvement in gasification combined cycle power generation with $\mathrm{CO}_{2}$ capture. IEA Greenhouse Gas R\&D Programme Report PH4/19: cases A.1 and B.3; May 2003.

[10] Consonni S. Performance prediction of gas/steam cycles for power generation. MAE Dept. Ph.D. Thesis no. 1983-T, Princeton, NJ: Princeton University; 1992

[11] Chiesa P, Consonni S, Lozza G, Macchi E. Predicting the ultimate performance of advanced power cycles based on very high temperature gas turbine engines. ASME Paper 93-GT-223; 1993.

[12] Martelli E, Consonni S, Amaldi E. A methodology for optimizing heat recovery steam cycles based on linear programming and particle swarm. In: Proceedings of the ASME- ATI-UIT 2010 conference on thermal and environmental issues in energy systems. Sorrento (Italy); May 2010.

[13] Martelli E. Optimal design of heat recovery steam cycles and heat integration. Lambert academic publishing; 2010. ISBN 978-3-8383-5884-0.

[14] Kubek D, Higman C, Holt N, Schoff R. $\mathrm{CO}_{2}$ capture retrofit issues. In: Proceedings of the gasification technologies. San Francisco, CA; October 16, 2007.

[15] Chiesa P, Lozza G. Using hydrogen as a gas turbine fuel. J Eng Gas Turbines Power 2005;127(1):73-81.

[16] Booras G. Feasibility study for an integrated gasification combined cycle facility at a Texas site. EPRI (Electric Power Research Institute) report 1014510. Palo Alto, CA; October 2006.

[17] Matchak TA, Rao AD, Ramanathan V, Sander MT. Cost and performance for commercial application of gasification combined-cycle plants. EPRI (Electric Power Research Institute) report AP-3486; April 1984.

[18] Chiesa P. Macchi E. A thermodynamic analysis of different options to break $60 \%$ electric efficiency in combined cycle power plants. J Eng Gas Turbines Power 2004;126(4):770-85.

[19] Oluyede EO, Phillips JN. Fundamental impact of firing syngas in gas turbines. In: Proceedings of ASME turbo expo 2007: power for land, sea and air, vol. GT2007-27385; 2007.

[20] Brdar RD, Jones RM. GE IGCC technology and experience with advanced gas turbines. GE Power Systems report GER 420; 2000.

[21] Siemens power generation. BENSON ${ }^{\circledR}$ once-through heat recovery steam generator; 2010. <http://www.energy.siemens.com/>.

[22] Martelli E, Kreutz T, Consonni S. Comparison of coal IGCC with and without $\mathrm{CO}_{2}$ capture and storage: shell gasification with standard vs. partial water quench. Energy Procedia 2009;1:607-14.

[23] Kunze C, Riedl K, Spliethoff H. Structured exergy analysis of an integrated gasification combined cycle (IGCC) plant with carbon capture. Energy 2011;36:1480-7.

[24] Jacobs Engineering (Amsterdam). ExerCom, calculating routine for Aspen Plus and Pro/II; 2011. <http://www.exercom.net>.

[25] Szargut J, Morris JR, Steward FR. Exergy analysis of thermal, chemical and metallurgical processes. New York: Hemisphere Publishing Corp; 1998.

[26] Lang YD, Biegler LT. A unified algorithm for flowsheet optimization. Comput Chem Eng 1987;11(2):143-58.

[27] EPRI (Electric Power Research Institute). TAG - technical assessment guide (electric supply). EPRI Report TR-102275, vol. 1 Rev. 7. Paolo Alto, CA; June 1993.

[28] Ogden J. Modeling infrastructure for a fossil hydrogen energy system with $\mathrm{CO}_{2}$ sequestration. In: Proceedings of the 6th international meeting on greenhouse gas control (GHGT-6). Kyoto, Japan; October 1-4, 2002.

[29] Vavatuk WM, 2002. Updating the CE plant cost index. Chemical Engineering 62-70; January 2002.

[30] Chemical engineering magazine. 2011. <http://www.che.com/pci/>. 